\title{
Habitat effect on hawksbill turtle growth rates on feeding grounds at Mona and Monito Islands, Puerto Rico
}

\author{
Carlos E. Diez ${ }^{1, *}$, Robert P. van Dam ${ }^{2}$ \\ ${ }^{1}$ Departamento de Recursos Naturales y Ambientales, PO Box 9066600, San Juan 00906-6600, Puerto Rico \\ ${ }^{2}$ Chelonia Incorporated, PO Box 9020708, San Juan 00902-0708, Puerto Rico
}

\begin{abstract}
Carapace length growth data were obtained from 197 hawksbill turtles Eretmochelys imbricata which were marked and recaptured from 1992 to 2000 at feeding grounds of Mona and Monito Islands, Puerto Rico. Straight-line carapace length (SCL) upon initial capture ranged from 20.0 to $84.5 \mathrm{~cm}$. SCL growth rates ranged from -0.59 to $9.08 \mathrm{~cm} \mathrm{yr}^{-1}$, were non-monotonic, and averaged highest in turtles measuring 34 to $35 \mathrm{~cm}$. Somatic growth rates varied by site within the study area, with turtles from the aggregation at Monito Island growing on average 2.1 times faster than residents of Mona Island habitats. Aggregation density and body condition index (body mass $\mathrm{SCL}^{-3}$ ) were also highest at Monito Island. Hawksbills recruiting to Monito Island at $23 \mathrm{~cm}$ SCL are expected to reach maturity less than 14.7 yr later. Growth rates in the turtles studied are similar to those reported for other Caribbean localities, but faster than hawksbills of the southern Great Barrier Reef, Australia. Hawksbills appear capable of utilizing habitats of widely varying quality, with prey abundance exerting a strong effect on somatic growth rates.
\end{abstract}

KEY WORDS: Hawksbill turtle $\cdot$ Eretmochelys imbricata $\cdot$ Growth rate $\cdot$ Carapace length $\cdot$ Habitat quality $\cdot$ Foraging ground $\cdot$ Puerto Rico

Resale or republication not permitted without written consent of the publisher

\section{INTRODUCTION}

Marine turtles are almost ideal subjects for somatic growth studies, as their mostly rigid carapacial structures can be measured with precision and are relatively invariant to short term fluctuations in nutritional condition. Growth increment data can yield important demographic parameters, such as age at maturation. Growth rates can also be used as indicators of turtle health, allowing for quality comparisons between foraging habitats and identification of environmental requirements. Yet growth has been little studied in marine turtles, in part due to the challenges of working in turtle foraging habitats over the long periods required to collect meaningful data.

The hawksbill turtle Eretmochelys imbricata is a medium-sized marine turtle with a circumtropical dis-

*E-mail: cediez@caribe.net tribution. Exploited over centuries, primarily for its carapacial scutes (tortoiseshell), the hawksbill is considered critically endangered throughout its range (Hilton-Taylor 2000). With few exceptions, populations in the Caribbean Region are generally depleted or declining (Meylan 1999).

The life history of hawksbill turtles remains poorly understood, but involves several stages and appears to be geographically complex. After an epipelagic posthatchling phase of unknown duration, immature hawksbills recruit to benthic habitats at a size of 20 to $30 \mathrm{~cm}$ carapace length. Once established, typically on coral reefs, immatures remain sedentary for periods of several years (van Dam \& Diez 1998b). Hawksbill turtles feed on a variety of invertebrates, but in many areas consume mainly sponges (Meylan 1988, van Dam \& Diez 1997b).

Only limited somatic growth information is available for hawksbill turtles. We are aware of only 3 published studies reporting the measurements taken of a size- 
able number ( $\mathrm{n}>10$ ) of foraging ground hawksbills. Chaloupka \& Limpus (1997) modelled growth rates measured in 44 immature turtles of the southern Great Barrier Reef; León \& Diez (1999) reported growth rates for 37 juveniles in the Dominican Republic; and Boulon (1994) gave growth rates for 13 immatures in the US Virgin Islands. In this paper, we present growth data obtained from 1992 to 2000, from 197 hawksbill turtles at study sites along the shores of Mona and Monito Islands, Puerto Rico.

\section{MATERIALS AND METHODS}

Mona Island $\left(18^{\circ} 5^{\prime} \mathrm{N}, 67^{\circ} 54^{\prime} \mathrm{W}\right)$ and Monito Island $\left(18^{\circ} 10^{\prime} \mathrm{N}, 67^{\circ} 57^{\prime} \mathrm{W}\right)$ are located midway in the Mona Passage between the Dominican Republic and Puerto Rico (inset, Fig. 1). The islands are managed as natural reserves by the Department of Natural and Environmental Resources of Puerto Rico. The study area consists of 3 sites representing 2 major habitat types: coral reefs along the south-west coast of Mona Island covering approximately $3.4 \mathrm{~km}^{2}$, and cliff walls along an $8.7 \mathrm{~km}$ section of the north coast of Mona Island and the $1.4 \mathrm{~km}$ perimeter of Monito Island (Fig. 1). Marine turtles in the study area are legally protected under the US Endangered Species Act.

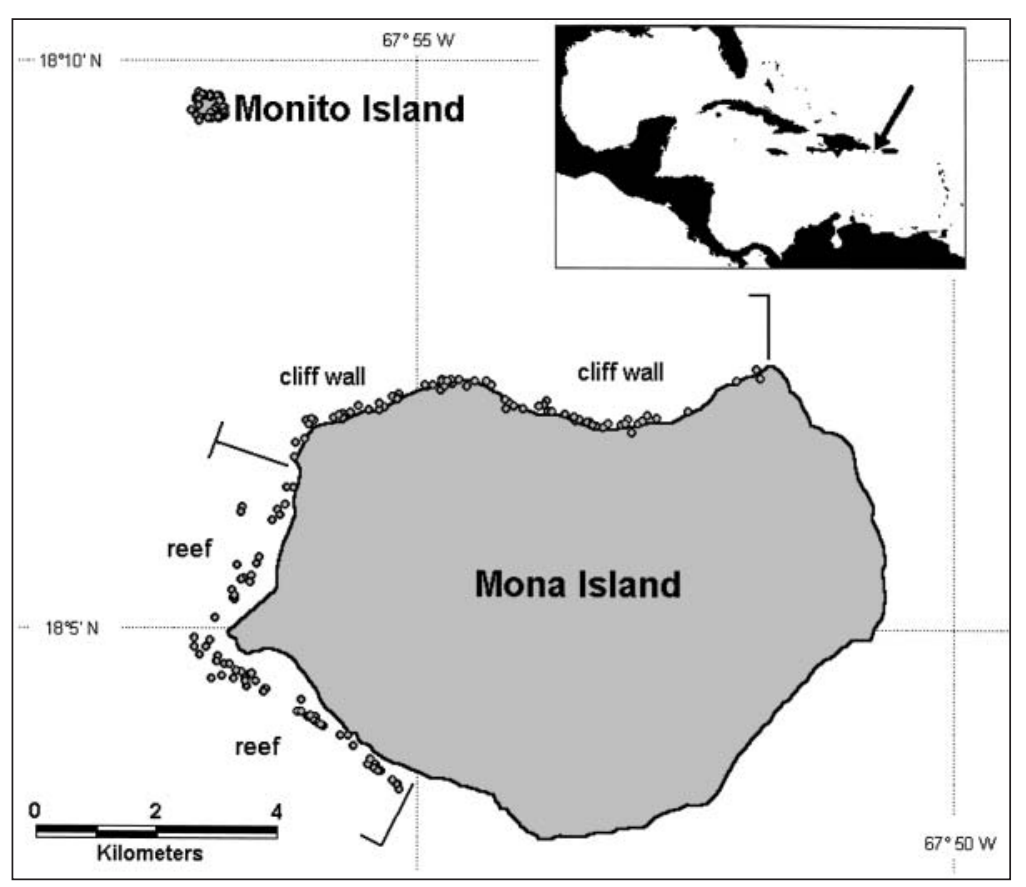

Fig. 1. Location and extent of reef and cliff wall study areas at Mona Island and Monito Island (cliff wall perimeter) with capture locations (o) of hawksbill turtles yielding growth information
The near-shore areas of Mona and Monito Islands provide foraging habitat for hawksbill turtles ranging from small juveniles to adults, and are also visited seasonally by adults reproducing on Mona (Thurston 1975). The assembly of resident immatures is derived from several breeding colonies in the Caribbean (Bowen et al. 1996, Bass 1999, Díaz-Fernández et al. 1999). The level of nesting activity on the beaches of Mona Island (over 500 nests $\mathrm{yr}^{-1}$ since 1998) makes it one of the largest breeding colonies in the Caribbean.

From 1992 to 2000 we visited the study area for 2 to 4 mo, generally in the period from July to October. We obtained growth data by the capture, marking and repeated recapture of turtles. All turtles were captured by hand through free diving or with SCUBA, and brought aboard a small boat for tagging and measurement. The animals were tagged using metal, plastic and/or passive integrated transponder (PIT) tags (for protocol see van Dam \& Diez 1999). To minimize interobserver measurement bias, each turtle was assigned to 1 of 2 observers (C.E.D. or R.P.v.D.) upon first measurement. Subsequent measurements were nearly always taken by that observer. Body size measurements recorded include straight-line carapace length (SCL; from nuchal notch to posteriormost marginal scute tip) and body mass. SCL was measured to the nearest $0.1 \mathrm{~cm}$ with 40,65 and $117 \mathrm{~cm}$ Haglof tree calipers. A note was made of which posterior marginal scute (left or right) was used in the first measurement; subsequent measurements were made to that scute. With this measurement protocol the average SCL intermeasurement discrepancy was $0.057 \mathrm{~cm}$ (determined from 39 pairs of turtle measurements taken under field conditions), which is smaller but not significantly different from the expected error of $0.071 \mathrm{~cm}$ for pairs of measurements with $0.05 \mathrm{~cm}$ rounding error (2-tailed $t$-test, $\mathrm{p}>0.05)$. Body mass was determined by weighing with $20 \times 0.2 \mathrm{~kg}, 50 \times 0.5 \mathrm{~kg}$ and $100 \times 1 \mathrm{~kg}$ Pesola, or $90 \times 1 \mathrm{~kg}$ Hanson heavy duty spring scales. Turtles were measured aboard a small boat where instability due to wave action reduced body mass measurement accuracy to an estimated 3 times scale resolution. Photographs were taken of all turtles after each capture, and included the entire carapace. After processing, turtles were released as close as possible to the site of original capture.

Measurements from turtles recaptured only once and within a period less than $0.8 \mathrm{yr}$, and from one individual suffering 
a severe carapace deformity (kyphosis), were excluded from the dataset. Six turtles exhibited breakage (chipping) of the posteriormost marginal scute tip. For these turtles SCL was inferred from proximate measurements using conversion formulas in van Dam \& Diez (1998a). Turtles were grouped by site within the study area for growth rate analyses. Three turtles that moved between sites during the course of our study were assigned to the site where they had remained longest. Individual growth rates were calculated for each recorded size increment and pooled by SCL in $1 \mathrm{~cm}$ bins. For example, a turtle that grew from 24.3 to $26.6 \mathrm{~cm}$ at a rate of $2 \mathrm{~cm} \mathrm{yr}^{-1}$ contributed the $2 \mathrm{~cm} \mathrm{yr}^{-1}$ value of the 24 ( $7 / 10$ weighted), 25, and $26 \mathrm{~cm}$ (both $6 / 10$ weighted) bins. The contents of each $1 \mathrm{~cm}$ bin were averaged over the number of contributing individuals to yield a representative growth rate by SCL. Bins were calculated for the entire size range of turtles encountered.

A turtle aggregation density index was calculated for each of the study sites by taking the total number of known resident turtles (recaptures) during the study period and dividing by the habitat surface area. The habitat utilized by turtles at the cliff wall sites was estimated from a study of diving behavior to extend up to $200 \mathrm{~m}$ from the cliff wall (van Dam \& Diez 1996). Including an approximate $50 \mathrm{~m}$ of vertical cliff face, habitat surface area was estimated at $0.25 \mathrm{~km}^{2}$ per linear $\mathrm{km}$ of cliff wall.

Seawater temperatures were measured at representative locations on the sea floor in each of the 3 study sites using waterproofed dataloggers (at 10 to $15 \mathrm{~m}$ depth; datalogers with $0.18^{\circ} \mathrm{C}$ resolution: Model HTI from 1995 to 1999, Model TBI32-05+ 37 from 1999, Onset Computer). Temperature loggers were calibrated against a quality $\mathrm{Hg}$ thermometer $\left(0.20^{\circ} \mathrm{C}\right.$ resolution) before each deployment (at least once annually).

\section{RESULTS}

During the 8 yr period of our study, a total of 437 size increments were obtained for 197 hawksbill turtles. At initial capture these turtles ranged in size from 20.0 to $84.5 \mathrm{~cm}$ SCL. Small juveniles (smaller than $35 \mathrm{~cm} \mathrm{SCL}$ ) are best represented in our dataset (Fig. 2A). Sampling was generally conducted during the same time of year (Fig. 2B), resulting in annual periodicity of the capture intervals. Time elapsed between the first and last capture of individual turtles had a median of $2.94 \mathrm{yr}$, with a median period between captures of $1.03 \mathrm{yr}$ (see Fig. 2C,D for interval distributions). The median intercapture distance between 336 pairs of observations from a total of 174 turtles was $0.32 \mathrm{~km}$ (range: 0.01 to $11.40 \mathrm{~km})$.
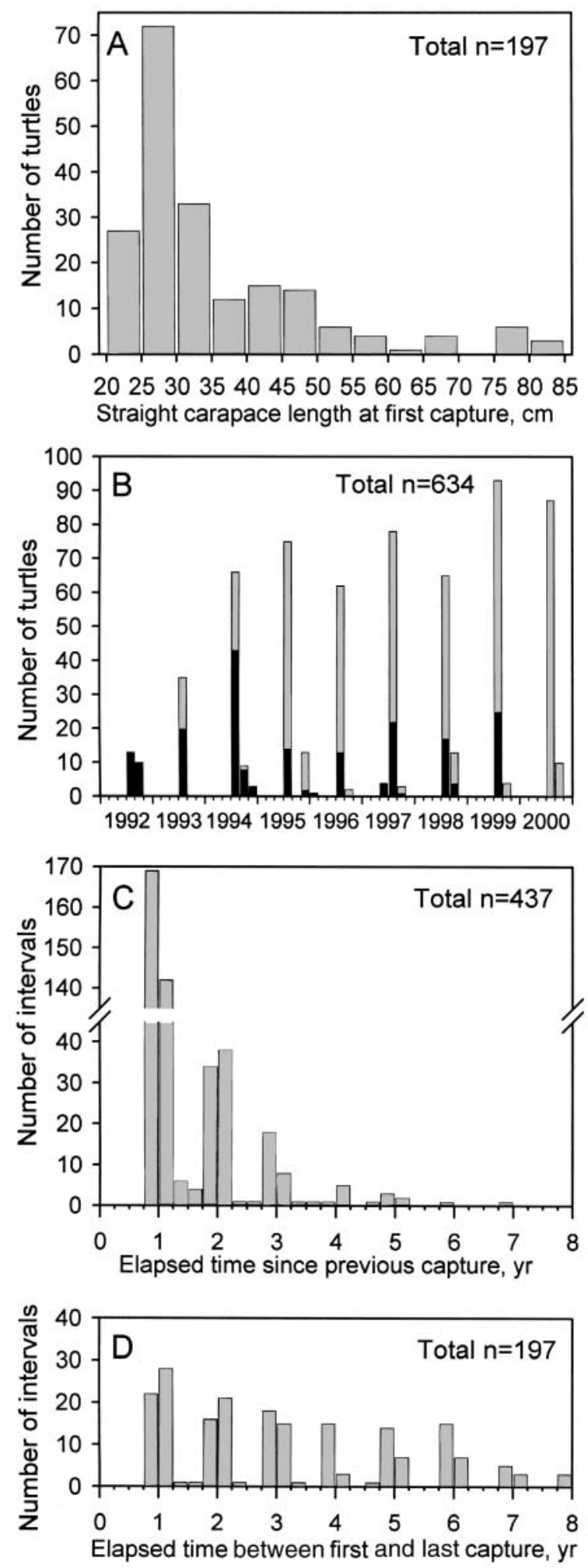

Fig. 2. Eretmochelys imbricata. (A) Size distribution of hawksbill turtles yielding growth data. (B) Number of turtles captured during the study period (black: turtles captured for the first time; grey: recaptures). (C,D) Distributions of intervals between turtle captures 
Calculated SCL growth rates ranged from -0.59 to $9.08 \mathrm{~cm} \mathrm{yr}^{-1}$ and varied by site in the study area (Fig. 3, bottom panel). Monito Island turtles grew on average 2.1 times faster with reference to SCL terms than those residing in the Mona Island sites. Small, recruitment size turtles $(<25 \mathrm{~cm}$ SCL) at the cliff wall habitats at both sites exhibited a growth spurt. Linear turtle growth peaked at about $35 \mathrm{~cm}$ SCL for all sites. On the Mona Island reefs, large turtles ( $\geq 68 \mathrm{~cm} \mathrm{SCL}$ ) in this growth dataset were all adult males, distinguishable by their long tails (see van Dam \& Diez 1998a). Measured growth in these turtles was slow to negligible.

Due to the difficulty of accurately measuring body mass in the field and the sensitivity of growth increment data to measurement error, individual body mass increments were not used to obtain body mass growth rates directly. Instead, power function regressions of body mass against SCL were calculated for pooled turtles from each study site (Body mass $=a \mathrm{SCL}^{b}$; Table 1, last column), followed by application of the derivative

$$
\delta(\text { body mass }) / \delta \mathrm{t}=a b \mathrm{SCL}^{b-1} \delta \mathrm{SCL} / \delta \mathrm{t}
$$

to yield body mass growth rates. Derived body mass growth rate estimates exhibited a monotonous rise until dipping slightly around $50 \mathrm{~cm}$ SCL at all study sites, then varying substantially without a consistent pattern in larger turtles (Fig. 3, middle panel).

The growth data collected from turtles throughout the range of 23 to $61 \mathrm{~cm}$ SCL at each of the study sites

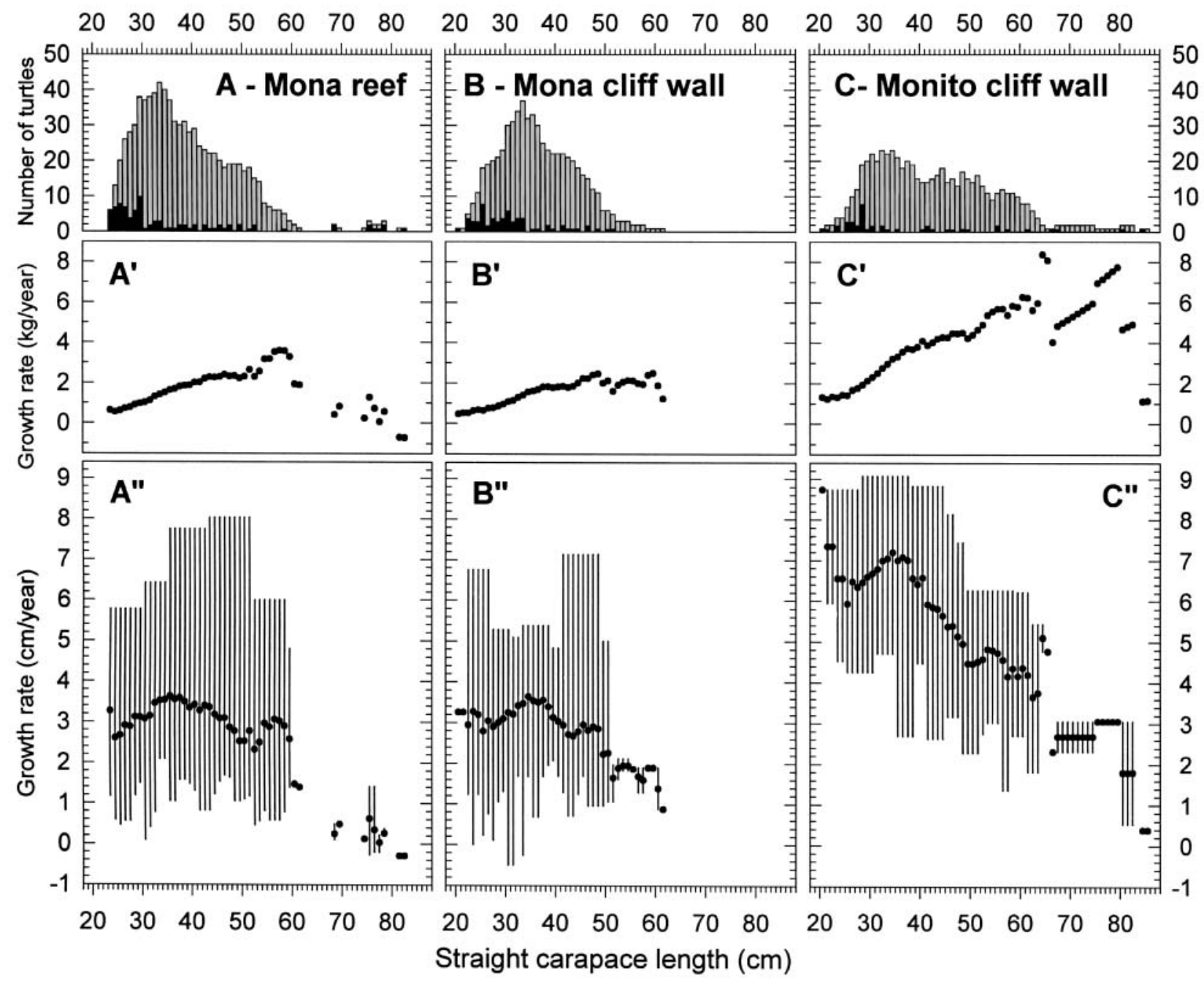

Fig. 3. Eretmochelys imbricata. Growth rates $(\bullet)$ of straight-line carapace length (SCL; in A", B", C") and derived body mass (in A', B', C'), for hawksbill turtles of 3 study sites at Mona and Monito Islands, Puerto Rico. Lines in A", B", C" illustrate the range of minimum growth rates among turtles contributing to the calculation of mean growth rates by $1 \mathrm{~cm}$ SCL intervals. Histograms $(A, B, C)$ indicate the number of individuals contributing to each calculated growth rate; black bars represent size of turtles at first capture 
Table 1. Eretmochelys imbricata. Parameters of the hawksbill aggregation at the 3 study sites. The area used by turtles in cliffwall habitats is estimated at $0.25 \mathrm{~km}^{2}$ per linear $\mathrm{km}$ of coastline (in parentheses) (from turtle diving behavior in van Dam \& Diez 1996). Body condition index is body mass $\mathrm{SCL}^{-3}$

\begin{tabular}{|c|c|c|c|c|c|}
\hline Site & Habitat size & $\begin{array}{l}\text { No. of turtles } \\
\text { (recaptures only) }\end{array}$ & $\begin{array}{l}\text { Aggregation } \\
\text { density index }\end{array}$ & $\begin{array}{l}\text { Body condition } \\
\text { index } \\
\left(10^{-4} \mathrm{~kg} \mathrm{~cm}^{-3}\right)\end{array}$ & $\begin{array}{c}\text { Regression } \\
\text { parameters } \\
\left(\text { body mass }=a \mathrm{SCL}^{b}\right)\end{array}$ \\
\hline Mona reef & $3.4 \mathrm{~km}^{2}$ & 82 & 24.1 & 1.18 & $\begin{aligned} a & =0.000115 \\
b & =3.009 \\
\mathrm{R}^{2} & =0.9926\end{aligned}$ \\
\hline Mona cliff wall & $\begin{array}{l}2.2 \mathrm{~km}^{2} \\
(8.7 \mathrm{~km})\end{array}$ & 63 & 28.6 & 1.16 & $\begin{aligned} a & =0.000101 \\
b & =3.046 \\
\mathrm{R}^{2} & =0.9900\end{aligned}$ \\
\hline Monito cliff wall & $\begin{array}{c}0.35 \mathrm{~km}^{2} \\
(1.4 \mathrm{~km})\end{array}$ & 41 & 120 & 1.24 & $\begin{aligned} a & =0.0000945 \\
b & =3.074 \\
\mathrm{R}^{2} & =0.9929\end{aligned}$ \\
\hline
\end{tabular}

make it possible to construct relative age at size plots by integrating the SCL growth curves of Fig. 3. Turtles starting at $23 \mathrm{~cm}$ SCL can be expected to reach $61 \mathrm{~cm}$ after $13.6 \mathrm{yr}$ if living on a Mona coral reef, after $16.1 \mathrm{yr}$ if residing along the cliff walls of Mona, or in $4.8 \mathrm{yr}$ if inhabiting the cliff coast of Monito Island (Fig. 4). The mean relative-age-to-size curve for the entire study area, weighted by turtle, indicates that hawksbills reach $61 \mathrm{~cm}$ SCL after 10.4 yr. Caution should be exercised with the interpretation of these curves, as the various error sources are cumulative, resulting in broader confidence intervals at higher SCL.

Water temperatures at sea floor level in the study area averaged $27.72^{\circ} \mathrm{C}$ over a 5 yr period, exhibiting a seasonal variation of around $4^{\circ} \mathrm{C}$ (Fig. 5). The habitats are thermally relatively similar, with temperatures on the solar warmed Mona reefs measuring a mean $0.13^{\circ} \mathrm{C}$ above average, and waters around the Mona and Monito cliff walls a mean of 0.12 and $0.01^{\circ} \mathrm{C}$ below average, respectively.

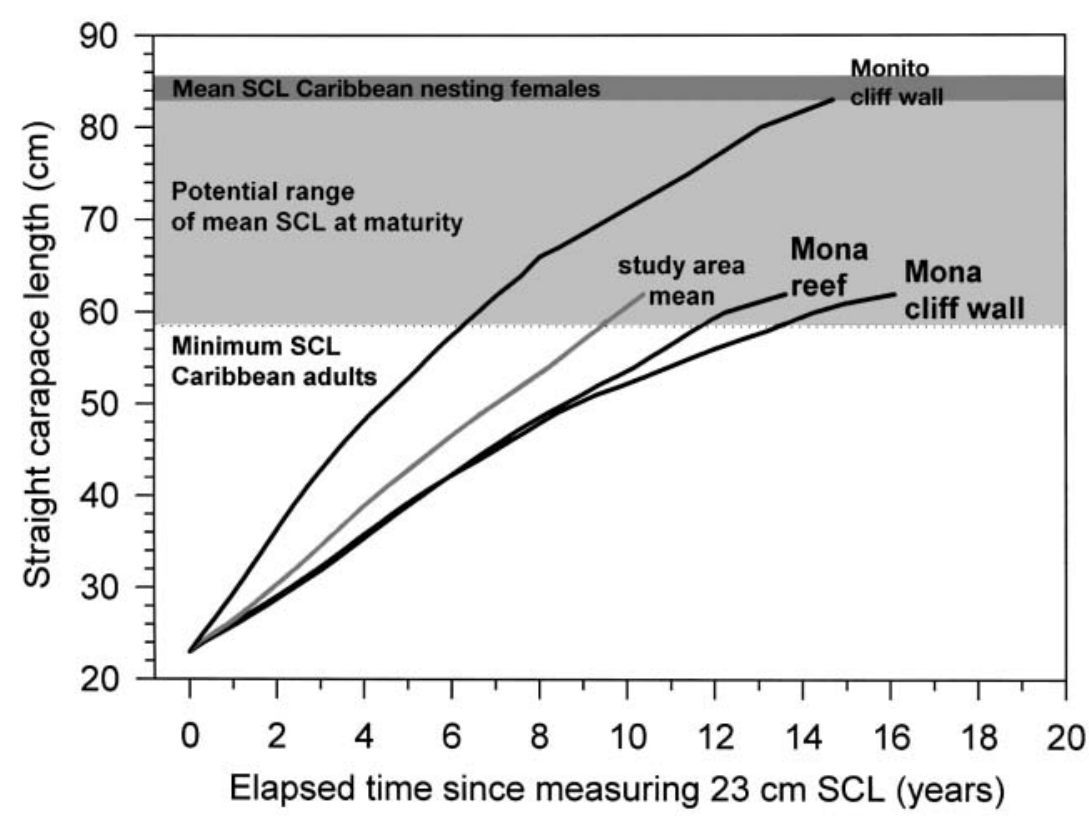

Fig. 4. Eretmochelys imbricata. Straight-line carapace length (SCL) growth curves for hawksbill turtles recruiting at $23 \mathrm{~cm}$ SCL to the 3 study sites at Mona and Monito Islands. Grey curve is the turtle-weighted mean for all sites. Indicated are the mean (Carr et al. 1966, Pritchard 1969, van Dam \& Sarti unpubl. data) and minimum size (Moncada et al. 2000) of adult Caribbean hawksbills (nesting females), delimiting the mean size at maturity, which is unknown

\section{DISCUSSION}

Somatic growth can be thought of as a process governed by an assortment of factors, both those intrinsic to the individual and those imposed by the environment. Explaining any observed variation in terms of contributing factors is one pathway to discern causal mechanisms. Any such analysis must first take into account the limitations imposed by any peculiarities of the study subjects, the sampling protocol and any errors associated with it.

\section{Sampling design and error sources}

The mark and recapture protocol used to collect growth data can be classified as a mixed longitudinal sampling design (Chaloupka \& Musick 1997). As with many other studies of growth in free-living marine turtles, the sex and age of our subjects 


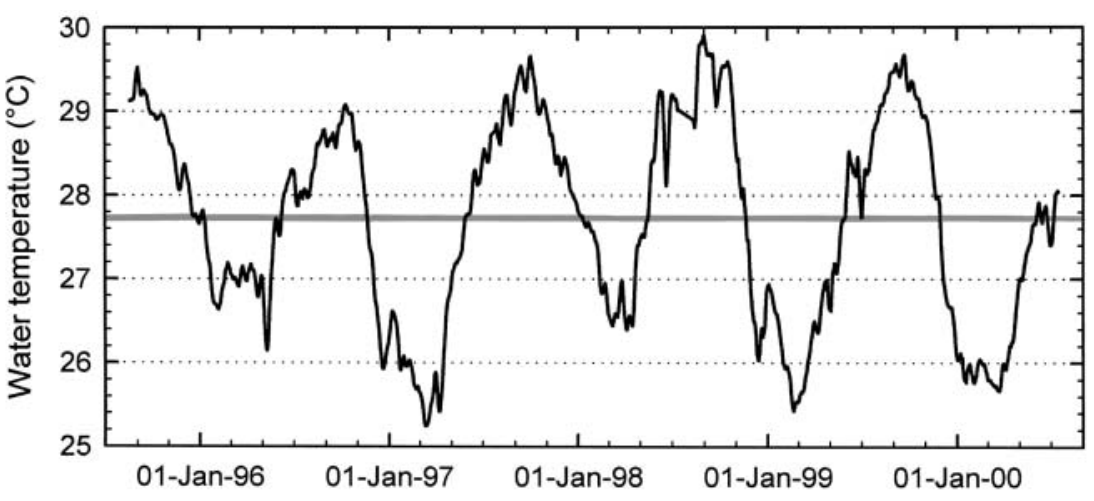

Fig. 5. Water temperature at Mona and Monito Islands. The temperature curve is a $7 \mathrm{~d}$ moving average of measurements made at 3 sites in the study area. The grey line indicates overall mean temperature from January 1, 1995 to January 1, 2000

should not have been expressed in our growth dataset.

Tag loss may also lead to bias in growth rate studies through the potential loss of identity and incorrect reassignment as a different individual. In van Dam \& Diez (1999) we estimated, for hawksbill turtles of the study area, that the probability of loss of identity through complete tag loss for the most commonly used tagging configuration after $3 \mathrm{yr}$ is 1 in 324. Extrapolation of this value to $8 \mathrm{yr}$, the duration of the current study, results in an estimated identity loss for 1 in 122 turtles. Although the quality of this estimate

was unknown. Turtles were thus grouped by linear size (SCL) for analysis. Therefore, potential sexual differences, cohort (age class) and sampling year effects cannot be isolated or quantified (see Chaloupka \& Musick 1997).

Identifiable error sources in our study include size measurement inaccuracies, seasonal sampling bias, turtle misidentification due to tag loss, and inclusion of turtles that are not in fact part of the feeding ground aggregation.

Size measurement errors are likely to be substantial in marine turtle studies because of the often difficult field conditions during measurement (e.g. turtle movement, weather, boat instability). Straight-line measures, such as SCL, are more accurate and reproducible than over-the-curve measurements (Bjorndal $\&$ Bolten 1989). Our mean SCL inter-measurement discrepancy of $0.057 \mathrm{~cm}$ is similar to the $0.046 \mathrm{~cm}$ reported for green turtles by Bjorndal \& Bolten (1988). Such low discrepancy is in part attributable to the elimination of inter-observer error, and is reflected in the low occurrence of length decrements ('negative growth') in our dataset. Hawksbill turtle carapaces can, and do, become shorter, primarily by abrasion or chipping of the marginal scutes. Negative growth can be expected to occur in individuals that are slow growing or live in very abrasive environments. During our study, length decrements were recorded in several adults captured on the Mona reefs and in 2 immatures off the Mona cliff wall (see Fig. 3), and serve to illustrate this point. Body mass is very difficult to measure accurately on a small, instable boat, and we therefore abstained from using mass measurements to infer growth rates directly (see 'Results').

Turtle growth is potentially affected by such seasonal effects as ambient temperature variation, prey condition, and storm prevalence. By sampling mostly at near 1 yr periods (see Fig. 2B), any seasonal effects is far from perfect, it indicates that for our sample size of 197 individuals any bias in the growth data caused by identity errors are likely to be very minor.

The adult turtles included in our study were predominantly males as judged by their long, protruding tails. These turtles may be local foraging ground residents, visitors to the breeding ground, or both, but their status could not be determined. If these adults were breeding visitors from other foraging grounds, then their growth information should have been excluded from our local feeding ground dataset (although males do feed locally during their $\sim 2$ mo stay on the Mona breeding grounds, pers. obs.). However, as no other growth data is available for male hawksbills in the Caribbean, we cannot assess the potential for bias that such misassignment might induce. Those adults captured on the Mona reefs (immediately in front of the nesting beaches) are more likely to be migrants than the Monito turtles (>7 km distant from beaches).

\section{Growth curve modelling}

Several parametric modelling methods have been used to extract growth curve and age information from size increment data in marine turtles (Frazer \& Ehrhart 1985, Bjorndal \& Bolten 1988). Most of these models (e.g. von Bertalanffy) assume a size-specific monotonic decrease in growth rates. The hawksbill turtles examined in this study, however, conform to a non-monotonic pattern, with growth rates consistently lower for animals in the 20 to $30 \mathrm{~cm}$ range than for those measuring 30 to $40 \mathrm{~cm} \mathrm{SCL} \mathrm{(Fig.} \mathrm{3).} \mathrm{While} \mathrm{the} \mathrm{parametric}$ models typically used in growth studies have the advantage of being concise, allowing for easy comparisons between growth curves, none of these simple models appear able to conform to the non-monotonic trends in our growth data. Partly in response to such 
difficulties, recent studies of marine turtle growth have used sophisticated, generalized additive modelling (GAM) approaches to determine growth curves and examine contributing factors, such as sex and year effects (e.g. Chaloupka \& Limpus 1997, Bjorndal et al. 2000). An important objective of these (and our) studies is to obtain representative growth curves (e.g. growth rate vs size), which with GAM are typically constructed as smoothed splines, sustained by a large number of (non-explicit) parameters. Because in our study we examine only the clear effect of habitat type, for which the dataset is easily separable, we prefer to present the slightly reduced original data over a modelling result that would lack fit and conciseness.

\section{Age at maturity}

Measuring age at maturity directly in free-living marine turtles is near impossible given the geographic scope and long time spans that any such effort would involve. We must therefore resort to a 'shotgun' approach of assembling growth data from many individuals that overlap in the individual size range. Curves which represent the relative age against size can be generated through the straightforward integration of growth rates (e.g. Fig. 4). However, inferring age at maturity from these curves requires at least 2 further parameters: mean absolute age at the start of the curve (23 cm SCL in Fig. 4), and mean size upon reaching maturity. Unfortunately, no data are currently available on the duration of the epipelagic phase of Caribbean hawksbills, from their first entrance into water at 4.0 to 4.2 cm SCL (Carr et al. 1966, van Dam \& Diez 1998a) until their appearance on benthic foraging grounds at around 20 to $30 \mathrm{~cm}$ SCL. Similarly, the mean size upon maturation has not been documented, but here we can at least assign observation-based minimum and maximum bounds to this parameter. The smallest mature Caribbean hawksbills are those documented by Moncada et al. (1999) based on Cuban nesting surveys and a very large fisheries-based dataset. Males measuring $68 \mathrm{~cm}$ SCL and larger were apparently all mature. Fifty percent of females in the range 76 to $80 \mathrm{~cm}$ SCL had already matured, and the smallest nesting female measured only $58.5 \mathrm{~cm}$ SCL. At Mona Island, the smallest adult observed was a male of $68.2 \mathrm{~cm}$ SCL (van Dam \& Diez 1998a). An upper limit on the mean size at maturity can be placed by the average sizes of nesting females, which are well documented throughout the Caribbean, from $83.1 \mathrm{~cm}$ SCL at Mona Island (van Dam \& Sarti unpubl. data), $83.8 \mathrm{~cm}$ SCL in Costa Rica (Carr et al. 1966), to $85.5 \mathrm{~cm}$ SCL in Guyana (Pritchard 1969). The average size at maturity of Caribbean hawksbills undoubtably lies between the smallest observed adult female and the mean size of nesting females, as illustrated in Fig. 4. This range is still too wide to yield firm age to maturity estimates. We can at least say that hawksbills residing at Monito are likely to reach maturity less than $14.7 \mathrm{yr}$ from the moment they pass the $23 \mathrm{~cm}$ SCL mark. Hawksbills in the other Mona habitats will take much longer to mature.

\section{Comparison with other aggregations}

Published growth data for hawksbills in nearby foraging ground aggregations are available for the the southern Bahamas (Bjorndal \& Bolten 1988; $\mathrm{n}=5$ ), US Virgin Islands (Boulon 1994; n = 13 turtles), and the southwestern Dominican Republic (León \& Diez 1999; $\mathrm{n}=37$ ). The hawksbills in these studies grew at rates similar to those found in the Mona reef and cliff wall sites, with exception of the Dominican Republic turtles. There, the turtles measuring 21 to $45.2 \mathrm{~cm} \mathrm{SCL}$ at initial capture grew on average $5.76 \mathrm{~cm} \mathrm{yr}^{-1}$, thus approximating the high growth rates reported here for Monito Island turtles. León \& Diez (1999) also mention an apparent habitat effect, with hawksbills at the Lanza Zó site growing faster than those captured elsewhere in their study area extending $\sim 40 \mathrm{~km}$.

Other significant, but unpublished studies yielding hawksbill growth data in the region include those at the Ría Lagartos Biosphere Reserve, Mexico (M. Garduño pers. comm.; $\mathrm{n}=76$ turtles), and southern Cuba (Republic of Cuba Report for CITES meeting 15 to 17 May 2001; $\mathrm{n}=22$ turtles). Hawksbills in the Gulf of Mexico and Caribbean habitats exhibit fast somatic growth, with reported growth rates similar in value to those measured in Monito Island turtles. A positive correlation between water temperature and growth rates was found for the Cuban hawksbills, with environmental temperature explaining $50 \%$ of the observed growth variation. Other habitat properties were not examined in these studies.

Chaloupka \& Limpus (1997) present growth curves based on data collected for 44 immature hawksbill turtles of the southern Great Barrier Reef. Growth rates in these Australian hawksbills exhibit a non-monotonic pattern, rising from 1.0 to $1.5 \mathrm{~cm} \mathrm{yr}^{-1}$ at $40 \mathrm{~cm} \mathrm{SCL}$, peaking at $2.2 \mathrm{~cm} \mathrm{yr}^{-1}$ (females) and $1.7 \mathrm{~cm} \mathrm{yr}^{-1}$ (males) at $55 \mathrm{~cm}$ SCL, then gradually descending to negligible growth (reported curved carapace lengths converted to SCL using Table 1 in Limpus 1992). Overall, immature hawksbills of the southern Great Barrier Reef grow much slower than their counterparts in the Caribbean. Chaloupka \& Limpus (1997) did not consider habitat effect on growth, though it is likely that a vast area such as the southern Great Barrier Reef encompasses a range of hawksbill habitats. 


\section{Habitat effect and aggregation density}

The major apparent factor effecting turtle growth is that of location (see Figs. $3 \& 4$ ), which suggests that substantial differences in habitat quality exist between Monito Island and the rest of the study area. Water temperatures are relatively homogenous throughout the study area, with the measured differences too small to have biologically significant effects on the turtles. A dietary study conducted in the study area from 1992 to 1995 indicated that turtles inhabiting the Mona and Monito cliff wall sites feed on the same narrow range of sponge species (primarily Geodia neptuni), whereas the Mona reef turtles preyed upon a much broader assortment of sponges (van Dam \& Diez 1997b). Although food type alone can therefore not explain the observed difference in growth rates between Mona and Monito cliff wall turtles, there are indications that food abundance is higher at Monito than elsewhere. Logistical difficulties have unfortunately prevented the direct measurement of food abundance in the study area. But there are key differences in the diving behavior of turtles from the 3 study sites: Monito turtles monitored with time-depth recorders made foraging dives on average for only $5.1 \mathrm{~h} \mathrm{~d}^{-1}$, versus 8.4 and $11.4 \mathrm{~h} \mathrm{~d}^{-1}$ recorded for similarsized Mona cliff wall and reef turtles, respectively (van Dam \& Diez 1996, 1997a, unpubl. data). Such differences reflect an enhanced ability by Monito turtles for locating and/or ingesting food, the simplest explanation for which is greater food availability. This hypothesis is further supported through comparison by study site of the body condition index (CI), a rough proxy for nutritional status and health: Monito hawksbills have on average a $\mathrm{CI}$ that is $6 \%$ greater than that of the Mona turtles (Table 1).

In their analysis of somatic growth in green turtles of the southern Bahamas, Bjorndal et al. (2000) found evidence for an inverse relation between aggregation density and growth rates, while reporting a positive correlation between green turtle body CI and growth rates. They interpreted this as an indication of limited nutrient availability and slower growth when green turtle feeding grounds were populated at higher densities. This contrasts with the relation between growth rates and the aggregation density index (Table 1) for hawksbills in our study area. Monito Island, where hawksbill growth is highest, is populated at densities over 4 times greater than at either the Mona reef or cliff wall habitats. Although we do not know the hawksbill carrying capacities of these areas, or whether these might have been reached, the marked differences in growth rates, aggregation densities, and body CI indicate that hawksbill aggregation density effects are unlikely to be as clear-cut as in the green turtles examined by Bjorndal et al. (2000). Habitat quality, and preferred prey abundance in particular, seem to be the key to understanding growth in hawksbill turtles, and with it, their aggregation dynamics. The biological and physical complexity of hawksbill habitats, coupled with the ability of these turtles to feed on the most cryptic of organisms, pose a significant barrier to increasing such understanding.

Acknowledgements. We thank H. Koyama, M. Bustamante, $M$. Schärer, numerous volunteers, and the staff of the Departamento de Recursos Naturales y Ambientales (DRNA) on Mona Island for assistance in the field. Research support was provided by the Japan Bekko Association, Departamento de Recursos Naturales y Ambientales (DRNA, Puerto Rico), US National Marine Fisheries Service (NMFS), Programa de Colegio Sea Grant (RUM-UPR), US Fish and Wildlife Service, Netherlands Foundation for the Advancement of Tropical Research (WOTRO), and Lerner Gray Fund for Marine Research. Work was conducted under permits from NMFS and DRNA.

\section{LITERATURE CITED}

Bass AL (1999) Genetic analysis to elucidate the natural history and behavior of hawksbill turtles (Eretmochelys imbricata) in the Wider Caribbean: a review and re-analysis. Chelonian Conserv Biol 3(2):195-199

Bjorndal KA, Bolten AB (1988) Growth rates of immature green turtles, Chelonia mydas, on feeding grounds in the southern Bahamas. Copeia 3:555-564

Bjorndal KA, Bolten AB (1989) Comparison of straight-line and over-the-curve measurements for growth rates of green turtles, Chelonia mydas. Bull Mar Sci 45:189-192

Bjorndal KA, Bolten AB, Chaloupka MY (2000) Green turtle somatic growth model: evidence for density dependence. Ecol Appl 10(1):269-282

Boulon RH Jr (1994) Growth rates of wild juvenile hawksbill turtles, Eretmochelys imbricata, in St. Thomas, United States Virgin Islands. Copeia 3:811-814

Bowen BW, Bass AL, Garcia-Rodriguez A, Diez CE and 5 others (1996) Origin of hawksbill turtles in a Caribbean feeding area as indicated by genetic markers. Ecol Appl 6(2): $566-572$

Carr A, Hirth H, Ogren L (1966) The ecology and migration of sea turtles. 6. The hawksbill turtle in the Caribbean Sea. Am Mus Novit 2248

Chaloupka MY, Limpus CJ (1997) Robust statistical modelling of hawksbill sea turtle growth rates (southern Great Barrier Reef). Mar Ecol Prog Ser 146:1-8

Chaloupka MY, Musick JA (1997) Age, growth and population dynamics. In: Lutz PL, Musick JA (eds) The biology of sea turtles, Chap 9. CRC Marine Science Series, CRC Press, Boca Raton, FL, p 235-278

Díaz-Fernández R, Okayama $T$, Uchiyama $T$, Carillo $E$, Espinosa G, Márquez R, Diez C, Koike H (1999) Genetic sourcing for the hawksbill turtle, Eretmochelys imbricata, in the northern Caribbean region. Chelonian Conserv Biol 3 (2):296-300.

Frazer NB, Ehrhart LM (1985) Preliminary growth models for green, Chelonia mydas, and loggerhead, Caretta caretta, turtles in the wild. Copeia 1985:73-79 
Hilton-Taylor C (2000) 2000 IUCN Red List of threatened species. IUCN, Gland, Switzerland

León YM, Diez CE (1999) Population structure of hawksbill turtles on a foraging ground in the Dominican Republic. Chelonian Conserv Biol 3(2):230-236

Limpus C (1992) The hawksbill turtle, Eretmochelys imbricata, in Queensland: population structure within a southern Great Barrier Reef feeding ground. Wildl Res 19: 489-506

Meylan AB (1988) Spongivory in hawksbill turtles: a diet of glass. Science 239:393-395

Meylan AB (1999) Status of the hawksbill turtle (Eretmochelys imbricata) in the Caribbean region. Chelonian Conserv Biol 3(2):177-184

Moncada F, Carillo E, Saenz A, Nodarse G (1999) Reproduction and nesting of the hawksbill turtle, Eretmochelys imbricata, in the Cuban Archipelago. Chelonian Conserv Biol 3(2):257-263

Pritchard P (1969) Sea turtles of the Guianas. Bull Fla Mus Nat Hist Biol Sci 13(2):85-140

Thurston J (1975) Observations on the ecology of the hawksbill turtle, Eretmochelys imbricata, on Mona Island, Puerto

Editorial responsibility: Otto Kinne (Editor),

Oldendorff/Luhe, Germany
Rico. In: Proc 11th Annual Meeting of the Association of Island Marine Laboratories of the Caribbean, May 1975, St. Croix, US Virgin Islands

van Dam RP, Diez CE (1996) Diving behavior of immature hawksbills (Eretmochelys imbricata) in a Caribbean cliff wall habitat. Mar Biol 127(1):171-178

van Dam RP, Diez CE (1997a) Diving behavior of immature hawksbill turtles (Eretmochelys imbricata) on the reefs of Mona Island, Puerto Rico. Coral Reefs 16(2):133-138

van Dam RP, Diez CE (1997b) Predation by hawksbill turtles on sponges at Mona Island, Puerto Rico. In: Lessios HA, Macintyre IG (eds) Proc 8th Int Coral Reef Symp, 24-29 June 1996, Smithsonian Tropical Research Institute, Balboa, Republic of Panamá 2:1421-1426

van Dam RP, Diez CE (1998a) Caribbean hawksbill turtle morphometrics. Bull Mar Sci 62(1):145-155

van Dam RP, Diez CE (1998b) Home range of immature hawksbill turtles (Eretmochelys imbricata) at two Caribbean islands. J Exp Mar Biol Ecol 220:15-24

van Dam RP, Diez CE (1999) Differential tag retention in Caribbean hawksbill turtles. Chelonian Conserv Biol 3(2): $225-229$

Submitted: July 12, 2001; Accepted: November 27, 2001

Proofs received from author(s): May 2, 2002 